\title{
Interactive comment on "A mass spectrometric multiple soil-gas flux measurement system with portable high-resolution mass spectrometer MULTUM coupled to automatic chamber for continuous field observation" by Noriko Nakayama et al.
}

\section{Anonymous Referee \#1}

Received and published: 8 April 2020

General comments: It's always very challenging to accomplish the high-precision and multi-gas measurements by any single detection technology. The present study attempts to simultaneously measure $\mathrm{N} 2 \mathrm{O}, \mathrm{CH} 4, \mathrm{CO} 2$, and $\mathrm{O} 2$ concentrations and fluxes based on the high-resolution multi-turn time-of-flight mass spectrometer (MULTUM) that attached to an automated chamber system. The authors emphasize a fundamental truth that "continuous multiple-gas flux and concentration measurements can be a powerful tool for tracking and understanding of underlying biological and physicochemi- 
cal processes." The present study precisely becomes a negative example of the fundamental truth, which neither achieves the real multi-gas flux measurements (only true for $\mathrm{CO} 2$ and $\mathrm{N} 2 \mathrm{O}$ fluxes) nor clarify the potential biogeochemical processes. The authors mention that "the developed system was used for continuous field soil-atmosphere flux measurements of greenhouse gases (GHGs: N2O, CH4, and CO2) and $\mathrm{O} 2$ with $1 \mathrm{~h}$ resolution." However, I only see the $\mathrm{CO} 2$ and $\mathrm{N} 2 \mathrm{O}$ fluxes in Fig.11. There is no valid flux data for $\mathrm{CH} 4$ and $\mathrm{O} 2$ either for the laboratory or field measurements. The present study only prove the ability of multi-gas concentration rather than flux measurements by the MULTUM system. The other most important highlight is to notice the different response of $\mathrm{CO} 2$ and $\mathrm{N} 2 \mathrm{O}$ fluxes to the first rainfall event in the present study. However, the authors draw the conclusion only from two hourly fluxes (two data points in Fig. 11), which have no spatial replicates (no error bars) and quality control processes. Specific comments: (1.) The manuscript NEEDS a thorough editing for language. There are too many grammatical errors and obscure sentences. (2.) I do not understand why the authors use different confidence levels ( 1 to 3 RSD) to calculate the limit of detection, instrument precision, minimum detectable fluxes and minimum quantitative fluxes. (3.) The concentrations of ambient gases rather than calibration gases are used to evaluate the instrument precision, why? How to avoid the impacts of daily variations in ambient gas concentrations, especially for $\mathrm{CO} 2$. A better way to present the instrument performance is the continuous measurement of calibration gases in the field laboratory. (4.) How to do the quality control of flux data, e.g. the statistical significance test of linear fitting between gas concentrations and sampling times? (5.) The future perspectives are absolutely arbitrary. "Coupling of proton transfer reaction (PTR) ionization sources with the MULTUM also makes it easier to observe BVOCs concentrations and soilatmosphere fluxes." Do you have any data to support the perspective? "We consider that the improvement in the detection limit by one order of magnitude can be relatively easy by retrofitting a larger vacuum pump to the MULTUM (from $50 \mathrm{l} / \mathrm{sec}$ to $250 \mathrm{l} / \mathrm{sec}$ ) and using a flux chamber with lower height (from $0.37 \mathrm{~m}$ to $0.2 \mathrm{~m}$ )." How to easily improve the detection limit when you measure the gas emissions from the soil-plant

Interactive comment
Printer-friendly version

Discussion paper

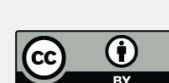


system rather than the bare soil? Technical corrections: (1.) The descriptions about how to calculate the minimum quantitative fluxes (Lines 270-285) should be the part of Materials and methods. (2.) Please specify what are the targets for the laboratory flux measurements? (3.) The conclusion is just a summary and repeated descriptions of results.

Interactive comment on Atmos. Meas. Tech. Discuss., doi:10.5194/amt-2019-389, 2020.

Interactive comment 